\section{The Practice of Wearing Surgical Masks during the COVID-19 Pandemic}

\author{
Cho-Han Chiang, Cho-Hung Chiang, \\ Cho-Hsien Chiang, Yee-Chun Chen
}

Author affiliations: National Taiwan University College of Medicine, Taipei, Taiwan (Cho-Han Chiang, Y.-C. Chen); Fu-Jen Catholic University, Taipei (Cho-Hung Chiang); Chung Shan Medical University, Taichung, Taiwan (Cho-Hsien Chiang); National Taiwan University Hospital, Taipei (Y.-C. Chen)

\section{DOI: https://doi.org/10.3201/eid2608.201498}

To the Editor: We read with interest the metaanalysis conducted by Xiao et al. (1) that found no significant reduction in influenza transmission with the use of surgical masks in the community, based on 10 randomized controlled trials. Nevertheless, mechanistic studies found that surgical masks could prevent transmission of human coronavirus and influenza virus infections if worn by infected persons (2). The authors pointed out the limitations of their study: small sample size and suboptimal adherence in the mask-wearer group (1). Recommendations on masks in the community vary across countries during the coronavirus disease (COVID-19) pandemic (3); studies have reported mixed results $(2,4,5)$.

Epidemiologic data may provide an alternative insight. As of April 3, 2020, Taiwan recorded 348 COVID-19 cases (1.46/100,000 population), of which $48(13.8 \%)$ were local cases. Singapore recorded 1,114 cases (19.07/100,000 population), of which 572 (51.3\%) were local cases. Taiwan and Singapore both employed stringent measures. Taiwan recommended the use of masks early in the pandemic. In contrast, Singapore did not recommend the use of masks until April 3 and initiated its Stay Home policy on April 7.

Before the 2003 severe acute respiratory syndrome coronavirus epidemic in Taiwan, only persons with open tuberculosis wore masks in public. During the epidemic, wearing a mask in public was stigmatized.
Thereafter, we educated the public to wear masks as a practice of respiratory hygiene. Although evidence is limited for their effectiveness in preventing transmission of severe acute respiratory syndrome coronavirus 2 , either for source control or to reduce exposure, the wearing of masks by healthy persons may prevent potential asymptomatic or presymptomatic transmission (3). This marginal reduction in transmission may produce substantial results, particularly when it is implemented early. Taiwan had the foresight to create a large stockpile of medical and surgical masks; other countries or regions might now consider doing so as part of future pandemic plans (3).

\section{About the Author}

Mr. Chiang is a medical student at National Taiwan University. His primary research interests are epidemiology and prevention of communicable diseases.

\section{References}

1. Xiao J, Shiu EYC, Gao H, Wong JY, Fong MW, Ryu S, et al. Nonpharmaceutical measures for pandemic influenza in nonhealthcare settings - personal protective and environmental measures. Emerg Infect Dis. 2020;26:967-75. https://doi.org/10.3201/eid2605.190994

2. Leung NHL, Chu DKW, Shiu EYC, Chan KH, McDevitt JJ, Hau BJP, et al. Respiratory virus shedding in exhaled breath and efficacy of face masks. Nat Med. 2020 Apr 3 [Epub ahead of print]. https:// doi.org/10.1038/s41591-020-0843-2

3. Feng S, Shen C, Xia N, Song W, Fan M, Cowling BJ. Rational use of face masks in the COVID-19 pandemic. Lancet Resp Med. In press 2020. https:/ / doi.org/10.1016/ S2213-2600(20)30134-X

4. Ng K, Poon BH, Kiat Puar TH, Shan Quah JL, Loh WJ, Wong YJ, et al. COVID-19 and the risk to health care workers: a case report. Ann Intern Med. 2020 Mar 16 [Epub ahead of print]. https://doi.org/10.7326/L20-0175

5. Bae S, Kim MC, Kim JY, Cha HH, Lim JS, Jung J, et al. Effectiveness of surgical and cotton masks in blocking SARS-CoV-2: a controlled comparison in 4 patients. Ann Intern Med. 2020 Apr 6 [Epub ahead of print]. https:// doi.org/10.7326/M20-1342

Address for correspondence: Yee-Chun Chen, Department of Internal Medicine, National Taiwan University Hospital No. 7 Chung-Shan South Rd, Taipei, Taiwan; email: yeechunchen@gmail.com 